\title{
A longitudinal study of e-commerce diversity in Europe
}

\author{
Adam Sadowski ${ }^{1} \cdot$ Karolina Lewandowska-Gwarda ${ }^{2}$. \\ Renata Pisarek-Bartoszewska ${ }^{1} \cdot$ Per Engelseth ${ }^{3}$ (i)
}

Accepted: 8 February 2021 / Published online: 6 March 2021

(c) The Author(s) 2021

\begin{abstract}
Owing to increased access to the Internet and the development of electronic commerce, e-commerce has become a common method of shopping in all countries. The purpose of this study is more precisely to research e-commerce diversity in Europe at the regional level and develop the conception of "E-commerce Supply Chain Management". Statistical data derived from the European Statistical Office were applied to analyse the spatial diversity of e-retailing. Assessments of the regional diversity of e-retailing applied geographic information systems and exploratory spatial data analysis methods such us global and local spatial autocorrelation statistics. Clusters of regions with similar household preferences related to online shopping were identified. A spatial visualisation of the e-retailing diversity phenomenon may be utilised for the reconfiguration of supply chains and to adapt them to actual household preferences related to shopping methods.
\end{abstract}

Keywords E-commerce $\cdot$ Internet access $\cdot$ Regional factors $\cdot$ Supply chain management $\cdot$ Spatial analysis $\cdot$ Space-time diversity

Per Engelseth

pen008@uit.no

Adam Sadowski

adam.sadowski@uni.lodz.pl

Karolina Lewandowska-Gwarda

karolina.lewandowska-gwarda@uni.lodz.pl

Renata Pisarek-Bartoszewska

renata.pisarek@uni.lodz.pl

1 University of Lodz, Faculty of Economics and Sociology, Institute of Logistics and Informatics, ul. Rewolucji 1905 r. 37, 90-214 Lodz, Poland

2 University of Lodz, Faculty of Economics and Sociology, Institute of Spatial Economics, ul. Rewolucji 1905 r. 37, 90-214 Lodz, Poland

3 Troms $\varnothing$ School og Business and Economics, UiT Norges Arktiske Universitet, Troms $\varnothing$, Norway 


\section{Introduction}

The purpose of this research is to determine the extent of e-commerce diversity in Europe at the regional level in the years 2010-2019. E-commerce is a wide-ranging phenomenon. In a broad sense, e-commerce is understood as any form of economic activity using electronic connections. Zwass [50] defines electronic commerce as "the sharing of business information, maintaining of business relationships, and conducting of business transactions by means of telecommunications networks".

The scope of e-commerce includes electronic markets, electronically supported entrepreneurial networks and cooperative arrangements. It refers to the application of information and communication technologies (ICTs) throughout the entire range of the value chain, from the beginning to its endpoint and the transformation of business processes. Theoretical approaches to e-commerce distinguish transaction cost theory, marketing, diffusion, information retrieval and strategic networking that can all be the focus of empirical research [45]. E-commerce on electronic markets includes various forms of functionality including sales, retail, and purchasing. All these imply trading. This study concerns e-retail with an empirical focus on the development of regional online shopping, therefore we discuss e-retail in general in the conceptual framework.

Empirical focus is directed to the retail sector. Previous research on e-commerce has mostly analysed the problem at the country level. This applies to international comparisons in which the figures for e-commerce refer to individual countries. A similar consideration concerns e-retail spending diversification studies which are also conducted at a national level and adopt the form of a crossnational case study covering only selected countries [26]. Research results at the level of individual countries only provide limited and general insights into e-commerce development. At the same time, they do not allow for an in-depth analysis of e-retail diversification across regions within a given country. Moreover, ICT diffusion means that the phenomenon of the spreading of new e-consumer shopping behaviour patterns is not exclusive to the national dimension.

For this reason, in this research, we assumed that e-retail is regionally diverse and the regions rather than in individual countries drives e-retail diffusion. Research on the diversity of e-retail in Europe in regional terms can contribute to explaining changes in the perception of ICT by customers of traditional retail outlets. Furthermore, knowledge about the concentration of e-customers in regions is valuable for e-SCM managers, including those who decide on the location of logistics facilities providing e-retail services. Knowledge about the pace of change over time in individual regions supports the planning process for new investments in logistics in the long perspective.

The foundations for the importance of studying e-commerce diversity over time are many. The Internet and e-commerce show different developmental trajectories in different regions and countries of the world. This is connected with national diversity in the diffusion of e-commerce use and impact, including such dynamic factors as global environment, national environment, national policy and adoption of e-commerce [18]. These dynamic factors promote and limit 
e-commerce development depending on the geographical region or country and its homo- or heterogeneity. Globalisation is a key force creating the ability of consumers and business actors to perceive commerce diversity in general.

Commerce (both traditional and electronic) is a complex phenomenon which may be considered from the point of view of both convergence and divergence theories, leading to completely different evaluations of its consequences $[5,35$, 43]. It is also connected ICTs and the Internet becoming increasingly more diffused, resulting in the changing perception of geographical obstacles to economic growth $[22,27]$. E-commerce is also a phenomenon perceptible at both a national as well as the smaller regional level, implying that diversity includes regional variation in the perception of e-commerce meanings and use.

This study is centred on Europe, in essence the European Union (EU) member states. Europe is characterised by considerable diversity in terms of the Gross Domestic Product (GDP) achieved, population density, demographic and social structure, customer behaviour patterns, access to the Internet and frequency of its use, which allows a assumption of e-commerce being regionally conditioned [17]. This also applies to the development of e-commerce logistics and access to distribution chains of products ordered over the Internet. Another important factor impacting on e-commerce diffusion is the costs, speed and flexibility of deliveries affecting the distribution channel value for the customer [47].

Available information and communication technology (ICT) enables access to Internet applications in national languages, reducing the information divide, contributing to the development of European cross-border e-commerce. Nonetheless, barriers occurring between countries indicate the presence of country-specific effects for e-commerce demand even after correction for differences in income, distance, delivery charges and delivery times, which influence the quality of services provided as well as attracting and keeping e-customers [25].

The following research questions guide our study of e-commerce diversity in Europe:

- What is access to the Internet like in European regions including whether the frequency of Internet use regionally diversified?

- What are the spatial patterns of regional clusters with similar online shopping patterns?

- Did any changes occur in e-retailing in European regions in the years 20102019 ?

We thereby also aim to develop a conception of E-commerce Supply Chain Management (e-SCM) by reflecting upon e-commerce as more than a "one size fits all" phenomenon. Statistical data derived from Eurostat describing e-retailing at the Nomenclature of Territorial Units for Statistics (NUTS) 1 level in 34 European countries was used as our main data source. The analysis employed Geographic Information Systems (GIS) and Exploratory Spatial Data Analysis (ESDA), using the ArcMap 10.5 and GeoDa software. This study provides analysed empirical evidence for the diversity of e-retailing at a regional level since it encompasses the entire European geographical area. The use of spatial analysis tools (GIS and ESDA), which are 
not commonly implemented in e-commerce research, creates ample opportunity for finding, for example, spatial patterns across Europe as a single geographical entity irrespective of national borders.

The study consists of six parts. Section 2 describes the theoretical background of the study and discusses in-depth the spatial dimension of e-commerce, factors affecting the diffusion of e-commerce, online shopping behaviours and e-commerce logistics. Section 3 presents the methodology - the database used in the study and the methods applied in the further analysis. Section 4 describes in detail the results of a data analysis and spatial analysis of e-retailing development in Europe in the 2010-2019 period. Section 5 discusses the results, while the final section provides general conclusions and indicates further directions of research.

\section{Literature review}

\subsection{Factors affecting the diffusion of e-commerce}

Based on a review of the literature comprising 174 articles on Operations Research and Logistics, Giménez and Lourenço [19] define E-SCM "as the impact that the Internet has on the integration of key business processes from end user through original suppliers that provide products, services, and information that add value for customers and other stakeholders". They underline that, along with positive results such as reduced costs or increased supply chain process efficiency, the implementation of Internet technology brings about certain concerns associated with culture and technology.

Mahmood et al. [30] conducted a cross-country study exploring factors significantly positively impacting on online shopping behaviours. The scope of data used in the study included 37 countries with 42,238 interviewed individuals derived from the "TNS Interactive-Global eCommerce Report". The results obtained led to the conclusion that online shopper behaviours are actually affected by interpersonal trust and e-shoppers' economic situation. Results showed that an increase of 1 percent in the standard deviation in the trust index, for example, was associated with an increase of 1.86 percent in on-line shopping. For the economic situation, the rise in online shopping was even higher-at 2.69 percent. Interestingly, there was no significant relationship between technological practical understanding and behaviours connected with online shopping. It is also worth mentioning that the study drew attention to the influence of culture on online shopping as a factor playing an extraordinary role in e-business, which requires in-depth research. E-commerce has accordingly a complex and multifaceted structure. Many combinations of factors influence e-commerce diffusion. This includes considerations of its barriers to adaptation limited in analyses to particular countries and regions.

Other examples of e-commerce diversity include Couclelis [14] who examined one particular soft effect of information and communication technologies of special interest to geography and regional science, related to the modification of individual activity patterns and the modification of a person's activity space 
associated therewith. She put forward a hypothesis on activity disintegration assuming that "it is not distance that is dead; it is activity that is disintegrating". The hypothesis presumes a potential spatial and temporal disintegration of activity related to shopping in the context of substituting other activities such as, for example, professional work. The research leads to the conclusion that, thanks to ICTs, spatial and temporal boundaries of customer behaviours may change so radically that traditional e-shopper behaviour assumptions can no longer be applied. Hernández et al. [21] analysed perceptions leading customers to shop online in Spain. In the study, they assumed the Technology Acceptance Model (TAM) and included three factors, i.e. Internet acceptance, frequency of use and satisfaction. The results of their research lead to the conclusion that Internet acceptance does not affect the frequency of Internet use in the context of online shopping. It was also emphasised that the characteristics of a country, from both the economic and social perspectives, should also be analysed regarding e-shopper behaviours. In respect of the social perspective, cultural differences are of key importance, assuming the form of two cultural e-purchasing characteristics: authority distance and uncertainty avoidance in the case of Spain.

Kauffman and Kumar [24] conducted a study aimed at determining a relationship between ICT readiness (e-readiness) and trade flows as well as R\&D. The results indicate a positive relationship among the studied factors, although the strength of the relationship depends on the country. The impact of ICTs on different parameters is simultaneous, e.g. wider Internet accessibility provides greater opportunities for e-commerce, but also for democracy development and health awareness. The results also confirm that the Internet use variable is significant solely for commerce and ICTs. It should be highlighted that the Internet facilitates communication and shopping, making them faster and, in many cases, more convenient. However, the results of research performed by Çikrıkci [12], applying the method of meta-analysis, confirmed the occurrence of a negative relationship between Internet use and wellbeing. The study assumed the components of well-being to be life satisfaction, psychological well-being and self-esteem, which may significantly vary among countries and regions depending on socioeconomic, demographic and ethnic structures.

Results of research carried out in the United Kingdom prove that age and income are crucial demographic discriminators of e-commerce usage, as is rural versus urban location, and distance from physical stores [13]. Conclusions drawn from their study indicate that, although e-commerce diffusion began in big cities such as London, it is currently not a trend limited solely to cities. There is evidence of growing e-commerce use in rural areas derives from increasing high-quality broadband Internet access.

Smith et al. [41] conducted a cross-cultural exploration of online shopping behaviours, comparing Norway, Germany and the USA, and juxtaposing common views on increasing similarities in cross-national customer demand preferences and shopping behaviours with the fact that they represent distinct cultures in terms of commonly examined frameworks. Their conceptual model was grounded in the technology acceptance model (TAM) [16]. The survey was administered to undergraduate business students from three different countries-Norway, Germany and the USA. The research results emphasise the pervasiveness of cultural influences upon 
consumer behaviour. Germans and Norwegians appear to base their use of online shopping entirely on perceptions that online shopping enables them to accomplish tasks that cannot be done as effectively in traditional retail settings. This constitutes a utilitarian approach to online shopping treated as facilitating the process of acquiring goods and services [11].

In research into omnichannel (coopetition between various supply chains) customer behaviours, Juaneda-Ayensa, Mosquera and Murillo [23] applied the UTAUT 2 (Unified Theory of Acceptance and Use of Technology) model with two additional variables: innovativeness and perceived security, to test 628 Spanish customers of the Zara shop, referred to as customers 3.0., i.e. shopping online along with taking advantage of traditional forms of sales. Their results indicate that personal innovativeness is the strongest predictor of a shopping intention in the omnichannel context. At the same time, they proved that perceived security did not influence omnichannel shopping intention, which is key evidence of the possibility to extend e-commerce to include more conservative customers who perceive online shopping as a high-risk activity.

\subsection{E-commerce logistics}

Shi, Chen and Sethi [40] conducted a study aimed at examining the possibility of forecasting the repetitiveness of online shopping and determining the heterogeneity of customers using general distribution. In their research, they assumed a typical Online-to-Offline $(\mathrm{O} 2 \mathrm{O})$ model, differing from the traditional Business-to-Consumer model (B2C) in the inclusion and coordination of deliveries by third party logistics. The proposed stochastic model of predicting future spending by e-customers considered solely historical purchase transactions, without knowing customers' demographic data and preferences.

Onstein et al. [36] included the spatial layout of freight transport and storage systems used to move goods between production sites and consumption places in e-commerce research. They identified three important research streams: Supply Chain Management (SCM), Transportation and Geography, based on the Systematic Literature Review (SLR) method, distinguishing modelling methods as well as strengths and limitations of each research stream. The contribution of the study is the identification of relationships among seven groups of factors affecting the distribution model adoption. These groups of factors are: (1) demand level, (2) service level, (3) product characteristics, (4) logistics costs (transport costs, inventory costs and warehousing costs), (5) labour and land availability, (6) accessibility and (7) contextual factors.

Basing their research on a sample of 562 Swedish retail firms using multiple regression analysis, Tolstoy et al. [44] revealed that actions consisting of adapting sales channels have a positive impact on international sales in online channels. This enabled generating new insights into how the geographical export scope negatively moderates the effect that international online sales channel adoption has on international sales. 
Cárdenas et al. [10] examined the issue of the e-commerce last mile in Belgium from the perspective of external costs of delivery. Their research results indicate that e-commerce consumption per capita is higher in rural areas, which means that individuals living outside urban areas buy more from online distribution channels. At the same time, in respect of the number of kilometres connected with e-commerce freight transport, the results obtained indicate that urbanised areas absorbed over a half of deliveries in the country, significantly contributing to considerable $\mathrm{CO}_{2}$ emissions. The spatial distribution of deliveries unambiguously indicates that the majority of e-commerce deliveries in Belgium are directed to three towns: Brussels, Antwerp and Ghent located in the North-Eastern part of the country.

$\mathrm{Wu}$ and Lin [46] employed unstructured data analytics for retrieving valuable business models of e-commerce logistics comprising 2370 documents for the period 2010-2016 from professional websites dedicated to e-commerce, using web crawling using Python programming. The results of this topic mining identified eight main topics regarding e-commerce logistics, one of which refers to the spatial and temporal diversity of e-commerce in Europe: Europe e-commerce trends. This indicates that Finns prefer bank transfer payments and Danes-credit card payments, while online shoppers in the Netherlands, Spain and Germany consider free shipping and delivery within 3-5 days to be important requirements. The research also proves that cultural differences to customising appropriate technologies of e-commerce logistics could increase the likelihood of the acceptance of innovative technology.

Research presented and discussed in this section reveals how the diffusion of E-commerce and reducing the existing divergence are strongly influenced by the presence of the online commerce distribution chain, which allows the high utility of this form of buying goods and services by households. The distribution chain configuration directly affects the logistic service level, subject to different expectations in particular countries and regions.

\subsection{Spatial dimensions of e-retailing}

Research into e-commerce spatial diversity has been dominated by approaches describing the phenomenon at the national level [4]. The approach of e-commerce spatial diversity analysis considering regions has been applied to a lesser extent. This also applies to the regional e-commerce approach, which is most commonly presented from the perspective of regional diversity within a single country [38]. As stated by Perrons [39], the new economy is characterised by globalisation whose inherent trait is the increasing use of information and communication technologies. Positive globalisation effects are compensated for by the widening digital divide between those who are active knowledge economy participants and those who are digitally excluded. Research results indicate that workers in the new economy can be organically connected and simultaneously part of the broadening digital divide concerning different spatial scales. By extending conclusions related to new media clusters researched by Perrons to include e-commerce assumes the dispersed occurrence of similar e-retail clusters. 
Due to the lack of physical boundaries in Europe and the ease of handling e-customers from any region, shopping patterns intertwine. This is also associated with a new approach to the location of logistics facilities designed to provide services to the European e-retail sector from the point of view of the availability of regions, not countries, as in the past. This also applies to the reconfiguration of supply chains and their adaptation to the requirements of e-customers in e-retail sales channels [48].

The growing importance of the regional approach to e-retail, supply networks and e-customer behaviour leads to a new way of presenting, analysing and assessing phenomena that were previously treated as exclusively national. Billón et al. [6, 7] in research on the spatial distribution of the Internet in EU firms, they showed the influence of the spatial effect on ICT adoption by firms in the enlarged EU. The obtained research results in the form of the determination of clusters of regions with similar characteristics are significant from the point of view of cohesion policy and the development of the information society in Europe. Similar results [8] were obtained in the spatial analysis of the distribution of ICT use in European regions. Research has confirmed sharp disparities in the level of Internet use in households at a regional level in Europe. Nevertheless, based on these results, the existence of a division between the north-south and east-west regions cannot be unequivocally confirmed.

Lutz [29] performed research applying the Exploratory Spatial Data Analysis of the Digital Single Market in EU countries, excluding Turkey and Iceland. It proved the occurrence of, both globally and locally, strong spatial autocorrelation and the north-south polarisation pattern. In the years 2011-2016, the digital divide remained very stable and lasting, which was noticeable in the case of Internet use and e-commerce. Spatial patterns of the e-commerce index and its rise indicate saturation in growth through low clusters around Belgium and Scandinavia, but not in the surrounding areas of London.

Lucendo-Monedero, Ruiz-Rodríguez and González-Relaño [28] performed research into inequalities in the digital development of households and individuals in Europe. The results indicate that the basis for development and reducing existing inequalities is broadband Internet access, which is nationally and regionally diversified. Mainstream research on the diversity of e-commerce and e-retail involves conducting comparisons at the national level and, to a lesser extent, in-depth analyses of regional diversity at the level of individual countries. At the same time, there is a scarcity of research focused on the regional presentation of e-commerce diffusion, which would assume that the existence of administrative divisions is not relevant to the development of e-retail. This approach is based on the assumption that there are clusters of regions similar to each other from the point of view of online shopping development, which are also associated with the level of broadband Internet access and the frequency of its use.

Zhang et al. [49] conducted an analysis of spatial patterns and factors affecting e-commerce in China. Results of their research prove that e-commerce development is associated with the phenomenon of the formation of spatial and temporal clusters. Fundamental social productivity and residents' standard of living ought to be indicated among the principal factors positively impacting on this phenomenon. At the same time, the calculated Moran's I statistics show that the geographical 
agglomeration of e-commerce in China is gradually weakening [15]. Another conclusion for China is the fact that e-commerce development differences between regions began to shrink.

The occurrence of spatial inequalities in access to the Internet was also confirmed in research by Sujarwoto and Tampubolon [42], who tested two hypotheses: normalisation and stratification in developing countries on the example of Indonesia in the years 2010-2012. Their results indicate that, although a continuous and significant increase in telecommunication technologies' diffusion in the country occurred in the final 10 years of the study period, digital media development was spatially unequal. This confirms the stratification theory referring to the occurrence of divergence and the deepening of the divide in Internet use in the cross-section of socioeconomic groups, but also in other cross-sections, such as urban-rural or urbansuburban areas. The study provided no evidence of the reduction or closing of the divide according to the normalisation thesis in the study period.

In a questionnaire survey carried out in France, Motte-Baumvol, Belton-Chevallier and Dablanc [34] put forward two research hypotheses to be tested. The first one-the efficiency hypothesis-posited that people with low accessibility tend to buy more online. The second-the innovation-diffusion hypothesis-presumed that urban residents are more open to innovations and technology. The authors believe that, due to the increasing pace of spatial Internet coverage growth, the innovationdiffusion hypothesis should reduce spatial differences in online shopping in highly urbanised areas and areas with low population density, e.g. small towns and rural areas. They conclude that the Internet can be perceived as an additional space for shopping, and be included by households in their daily activities. They also assert that the propensity for online shopping is higher for suburban households in particular with those households being the main online shopping group. Furthermore, they note that online shopping considerably increases spatial accessibility with no need to travel to collect parcels.

Both e-retail and e-commerce diffusion are associated with an increase in Internet access. Changes in patterns of use as well as online customer experience in e-retail and technological know-how, which leads to an increase in e-trust and consumer confidence $[1,31,32]$. The spread of e-retail is associated with e-trust and is much more developed in countries and regions with high GDP and which are geographically, politically and economically stable [9]. They provided empirical evidence of this and, with the use of linear regression analysis, calculated that the correlation coefficient between IDI (Information and Communication Technologies Development Index) and GDP (Gross Domestic Product) is very high and amounts to 0.921 . Although this reductionist approach provides knowledge about general dependencies between ICT diffusion and GDP, it fails to explain the causes of regional diversity, and does not take into account other factors (e.g. socioeconomic, demographic or cultural) affecting e-retail.

The absorption of ICT and the increase in broadband Internet access by European societies demonstrate a varied pace of change over time, and it is not imperative to affect Internet use to make online purchases. Approaching e-commerce with a focus on regional diversity is not clearly confirmed in previous studies of e-commerce. Some study of online shopping has focussed on the north-south scheme of division 
of Europe. Therefore, classifying clusters of e-commerce perception and use from the point of view of e-logistics and e-customer service helps fill a current research gap. It is vital to know the dynamics of changes in e-retailing in European regions in the years 2010-2019, especially from the standpoint of the convergence process.

\section{Methodology}

\subsection{Data}

The analyses of e-retailing in Europe were performed based on statistical data available at the European Statistical Office (the source of data was Regional Digital Economy and Society). In order to show the most complete picture of e-retail in Europe, in addition to the European Union countries (Austria, Belgium, Bulgaria, Croatia, Cyprus, the Czech Republic, Denmark, Estonia, Finland, France, Germany, Greece, Hungary, Ireland, Italy, Latvia, Lithuania, Luxembourg, Malta, the Netherlands, Poland, Portugal, Romania, Slovakia, Slovenia, Spain, Sweden and the United Kingdom), the analyses also included Iceland, Montenegro, Northern Macedonia, Norway, Switzerland and Turkey-i.e. 34 European countries. The main goal of the research was to analyse the diversity of e-retail in Europe at the regional level. Therefore, the most appropriate way to conduct the analysis seemed to be at the NUTS 2 level, which represents the basic regions for the application of regional policies. Nevertheless, due to the lack of statistical data on e-commerce at the NUTS 2 level for some countries (the largest data gaps occurred in the case of France, Germany, Poland, Turkey and the United Kingdom), the analyses were carried out for NUTS 1-major socio-economic regions-i.e. 117 spatial units.

The analysed variables describing e-commerce were:

- FI Frequency of Internet access: once a week (including every day), percentage of individuals;

- $A I$ Households with access to the Internet at home, percentage of households;

- OI Individuals who ordered goods or services over the Internet for private use, last online purchase: in the 12 months, percentage of individuals.

Statistical data were collected for the years 2010-2019. Unfortunately, there were some small gaps in the database, especially in the case of France, where information for NUTS 1 was available until 2014. Due to the fact that an important element of the research was to analyse e-retail changes over time, in order not to reduce the sample scope (data for most spatial units have been available since 2010), the missing data were supplemented on the basis of trends.

Descriptive statistics for the variables are presented in Table 1. 
Table 1 Descriptive statistics for variables. Source: own elaboration

\begin{tabular}{|c|c|c|c|c|c|}
\hline & Minimum & Mean & Median & Maximum & $\begin{array}{l}\text { Standard } \\
\text { deviation }\end{array}$ \\
\hline \multicolumn{6}{|c|}{ FI (frequency of internet access: once a week) } \\
\hline 2010 & 19 & 61.8 & 65 & 92 & 18.1 \\
\hline 2011 & 21 & 64.6 & 68 & 94 & 17.8 \\
\hline 2012 & 23 & 66.8 & 70 & 95 & 17.3 \\
\hline 2013 & 23 & 69.0 & 72 & 95 & 16.9 \\
\hline 2014 & 29 & 72.0 & 75 & 97 & 15.7 \\
\hline 2015 & 23 & 73.6 & 76 & 97 & 15.2 \\
\hline 2016 & 39 & 76.5 & 79 & 98 & 13.6 \\
\hline 2017 & 40 & 78.6 & 80 & 98 & 12.4 \\
\hline 2018 & 47 & 81.2 & 83 & 99 & 10.8 \\
\hline 2019 & 53 & 83.5 & 85 & 98 & 9.7 \\
\hline \multicolumn{6}{|c|}{ AI (households with access to the internet at home) } \\
\hline 2010 & 18 & 66.1 & 67 & 92 & 16.6 \\
\hline 2011 & 20 & 68.9 & 71 & 95 & 15.8 \\
\hline 2012 & 22 & 71.7 & 74 & 95 & 15.5 \\
\hline 2013 & 27 & 74.2 & 77 & 96 & 15.1 \\
\hline 2014 & 44 & 77.6 & 78 & 97 & 12.4 \\
\hline 2015 & 52 & 80.0 & 80 & 97 & 10.7 \\
\hline 2016 & 57 & 83.3 & 83 & 97 & 9.2 \\
\hline 2017 & 64 & 84.9 & 85 & 99 & 8.4 \\
\hline 2018 & 69 & 87.2 & 88 & 99 & 7.1 \\
\hline 2019 & 69 & 89.3 & 90 & 99 & 6.3 \\
\hline \multicolumn{6}{|c|}{$\begin{array}{l}\text { OI (individuals who ordered goods or services over the internet for } \\
\text { private use) }\end{array}$} \\
\hline 2010 & 1 & 36.6 & 36 & 75 & 24.1 \\
\hline 2011 & 1 & 39.3 & 43 & 82 & 24.4 \\
\hline 2012 & 2 & 41.5 & 44 & 78 & 24.2 \\
\hline 2013 & 2 & 43.9 & 46 & 83 & 24.7 \\
\hline 2014 & 3 & 46.8 & 49 & 86 & 24.1 \\
\hline 2015 & 3 & 48.8 & 51 & 88 & 23.9 \\
\hline 2016 & 4 & 50.7 & 54 & 90 & 23.8 \\
\hline 2017 & 4 & 53.0 & 58 & 88 & 23.3 \\
\hline 2018 & 5 & 55.1 & 59 & 89 & 22.2 \\
\hline 2019 & 7 & 58.5 & 62 & 92 & 21.7 \\
\hline
\end{tabular}

\subsection{Methods}

In order to characterise the spatial structure of e-retail in European regions, basic methods of Exploratory Spatial Data Analysis, such as global and local spatial autocorrelation statistics, were used. Spatial autocorrelation can be defined as the 
coincidence of value similarity with locational similarity. Positive spatial autocorrelation occurs when high or low values of a random variable tend to cluster in space. In turn, negative spatial autocorrelation occurs when geographical areas tend to be surrounded by neighbours with dissimilar values [3].

Moran's I statistic is the most commonly used indicator of global spatial autocorrelation. It was introduced by Moran [33], then adapted for the purpose of spatial analyses and popularised by Cliff and Ord [37]. In essence, it is a crossproduct statistic between a variable and its spatial lag, with the variable expressed in deviations from its mean.

$$
I=\frac{\sum_{i=1}^{n} \sum_{j=1}^{n} w_{i j}\left(x_{i}-\bar{x}\right)\left(x_{j}-\bar{x}\right)}{\sum_{i=1}^{n}\left(x_{i}-\bar{x}\right)^{2}}=\frac{\mathbf{z}^{T} \mathbf{W} \mathbf{z}}{\mathbf{z}^{T} \mathbf{z}}
$$

where: $n$-number of observations; $x i, x j-v a l u e s$ of variable $x$ in locations $i$ and $\mathrm{j}$; - mean value of xi observations; wij-elements of spatial weights matrix $\mathrm{W} ; \mathrm{z}-\mathrm{a}$ vector which takes the form: $\mathbf{z}=\left[\begin{array}{c}z_{1} \\ z_{2} \\ \ldots \\ z_{n}\end{array}\right]$, where the form: $z_{i}=x_{i}-\bar{x}$.

Values for Moran's I statistic fall in the interval. Values above zero indicate the presence of positive spatial autocorrelation and below zero-the occurrence of negative spatial autocorrelation. In the event that there is no correlation between adjacent values, the expected value is close to zero. In order to verify hypotheses concerning spatial autocorrelation (H0: observed values of the variable are randomly distributed, hence there is no spatial autocorrelation between specific locations, H1: there is spatial autocorrelation), randomisation tests are performed.

In order to identify spatial relationships of a given variable in a specific location, local indicators of spatial association (LISA) developed by Anselin [2] are used. One of them is a local Moran's I statistic. A characteristic feature of these measures is that the sum for all locations is proportional to the value of the global autocorrelation measure $\Sigma \mathrm{iLi}=\gamma \mathrm{M}$. LISA provide a more detailed insight into the structure of spatial distribution of the studied variable by indicating, among others, statistically significant clusters of spatial units characterised by similar values of the analysed variable.

\section{Findings}

Figures 1, 2 and 3 present values of the analysed variables in selected years (2010, 2015 and 2019) as well as the pace of change in the years 2010-2019 and absolute growth in the years 2010-2019. It should be highlighted that, for the clarity of maps, some islands belonging to Spain, Portugal and France were removed from the visualisations of the results, but they were not excluded from the analyses. The 
classification method for all maps was an equal interval, apart from maps presenting the pace of change where the natural brakes method was used.

Figure 1 presents statistical data and analyses for the FI variable. The maps clearly show the considerable spatial diversity of the variable in Europe. The largest percentage of the population using the Internet at least once a week in

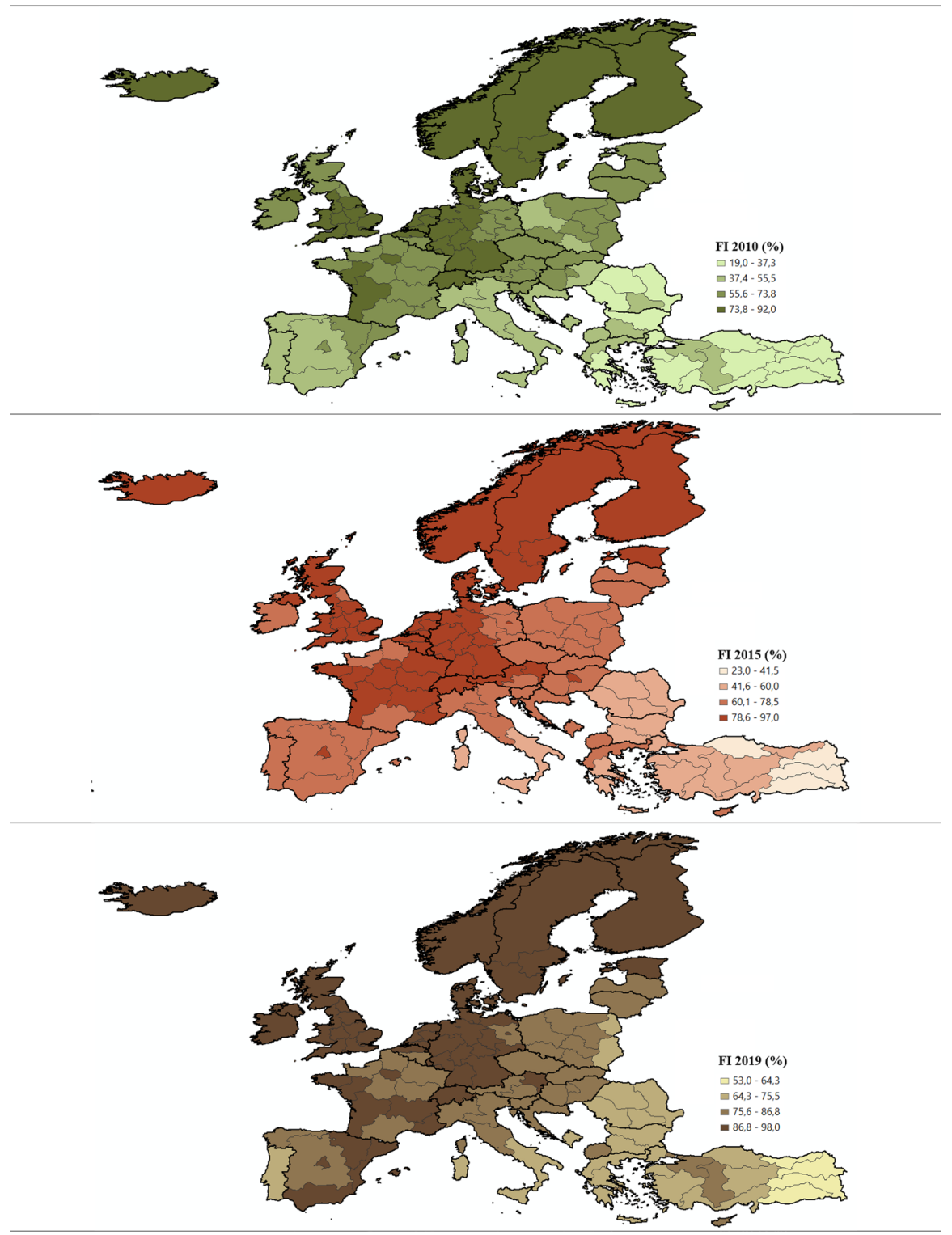

Fig. 1 Frequency of internet access: once a week (\% of individuals) in 2010, 2015, 2019, pace of change 2010-2019 and absolute growth 2010-2019 (percentage points). Source: own elaboration in ArcMap 


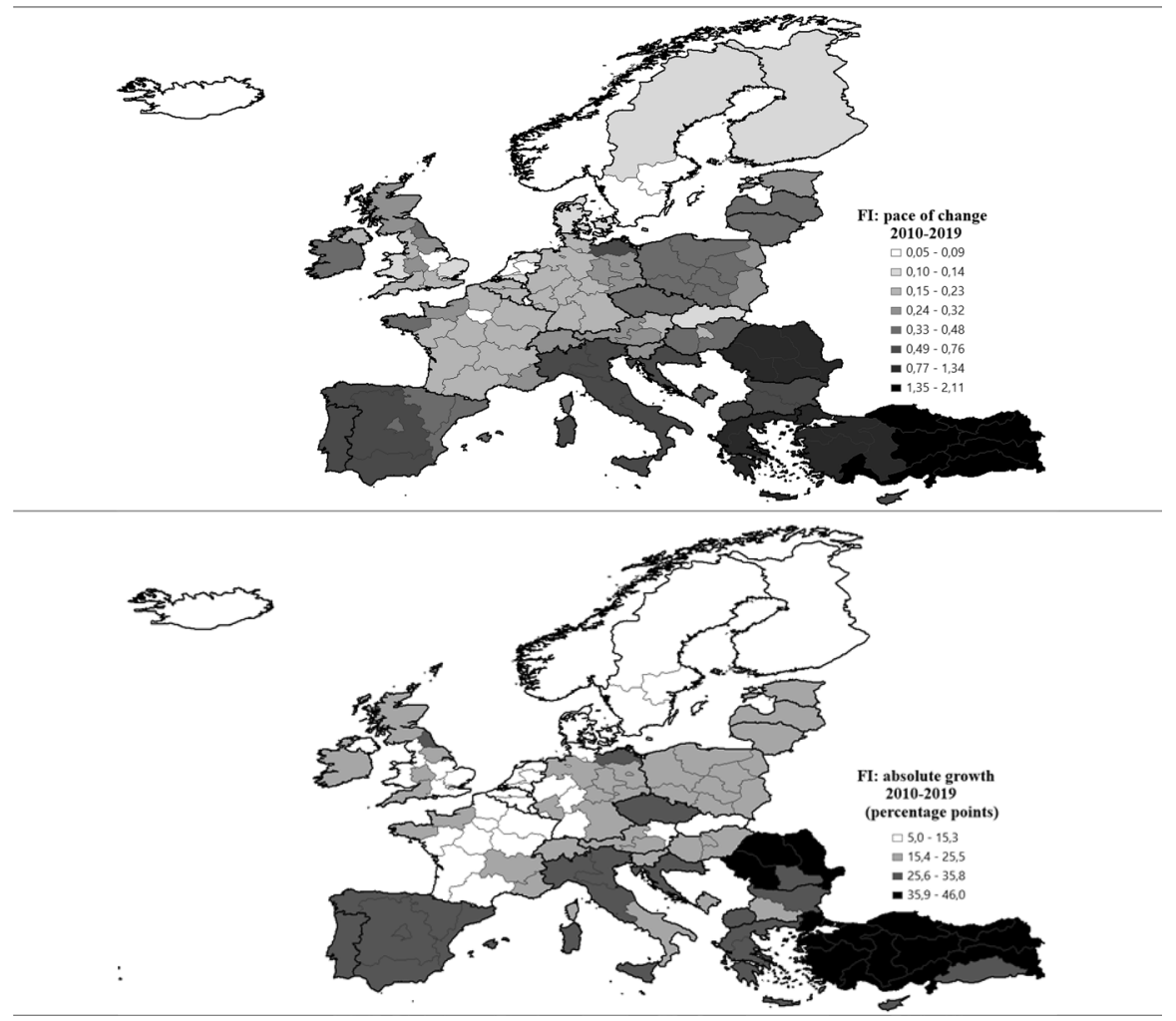

Fig. 1 (continued)

all the analysed periods was found in regions situated in the Northern and Western parts of Europe, particularly in Iceland, Norway, Sweden, Finland, the United Kingdom, the Netherlands, Denmark, Germany, Switzerland and partly in France. In 4 regions (about $3.4 \%$ of the analysed spatial units) in 2010 and in as many as 40 regions (about $34 \%$ of units) in 2019 , more than $90 \%$ of the population used the Internet at least once a week. The lowest values of the variable were observed in regions located in Southern and Eastern Europe, i.e. Turkey, Greece, Bulgaria, Romania, in the Eastern parts of Poland, Croatia, Italy and in Portugal. The minimum variable values in both 2010 and 2019 were reported in the regions: Kuzeydogu Anadolu (Turkey) and Güneydogu Anadolu (Turkey), although they rose from 20 to $59 \%$ and 53\%, respectively. The variable values increased in all the regions. The highest pace of change in the years 2010-2019, above 1, occurred in regions located in Turkey and Romania. In turn, a rise in the variable values above 0.5 was observed in most regions situated in Southern Europe. The highest absolute growth was reported in the region of Orta Anadolu (Turkey), where the variable value rose by 46 percentage points from 28 in 2010 to $74 \%$ in 2019 .

Figure 2 shows the values of the AI variable which, similarly to FI, was characterised by significant spatial diversity in Europe. It can be seen on the maps 


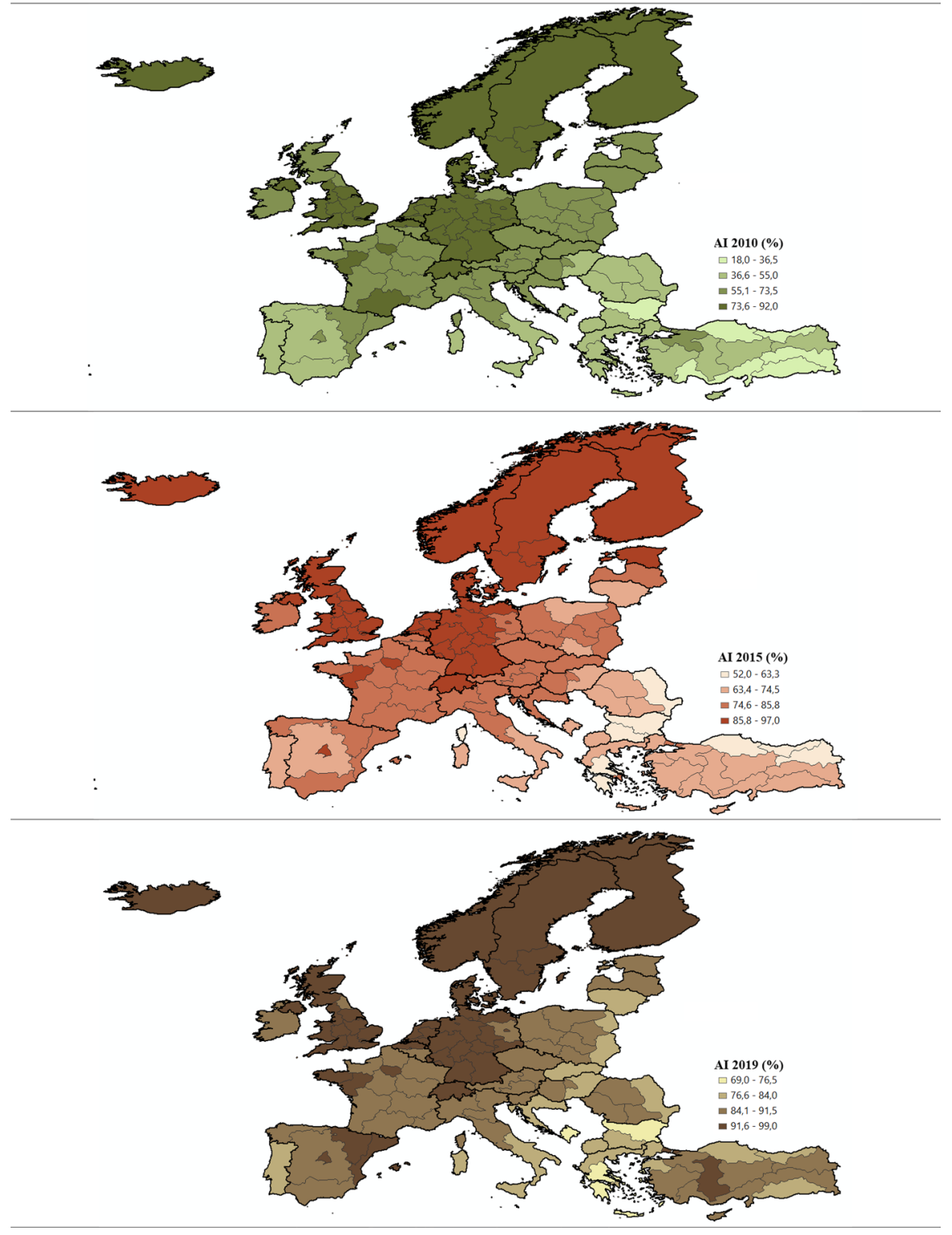

Fig. 2 Households with access to the internet at home (\% of households) in 2010, 2015, 2019, pace of change 2010-2019 and absolute growth 2010-2019 (percentage points). Source: own elaboration in ArcMap

that the largest percentage of the population with Internet access at home in all the analysed periods occurred in regions located primarily in Iceland, Norway, Sweden, Finland, the Netherlands, Denmark, the United Kingdom, Germany and Switzerland. A very high level of the variable, above $90 \%$, was noted as early as 


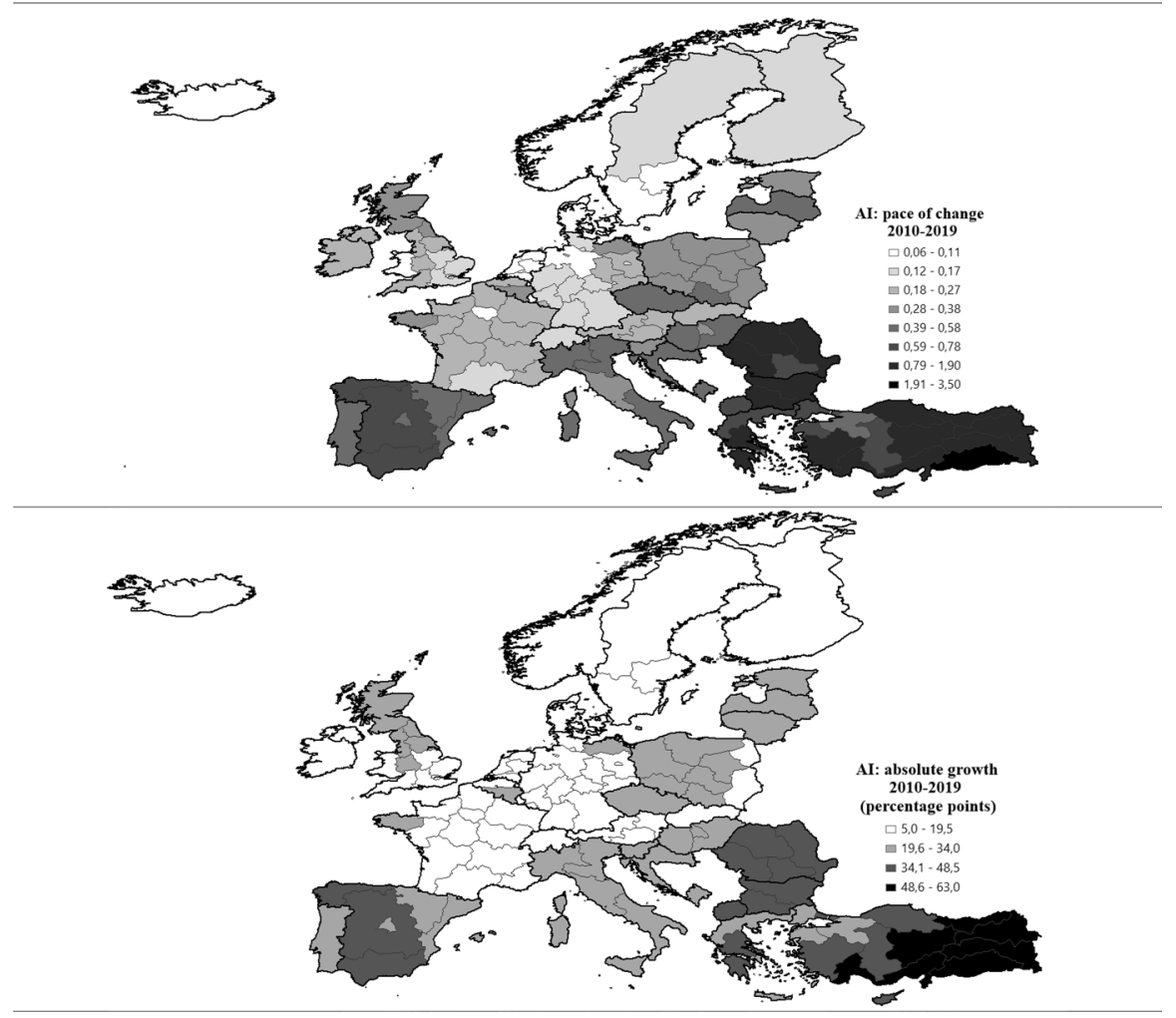

Fig. 2 (continued)

in 2010 in 7 regions (about 6\%) situated in the Netherlands, Finland, Sweden and Iceland. In 2019, similarly high values were reported in as many as 65 regions, which accounted for about $56 \%$ of the analysed spatial units. The lowest variable values in the whole analysed period were observed in Eastern Europe, in regions of Turkey, Greece, Bulgaria and Romania. In 2010, the minimum value of the variable at $18 \%$ was observed in the Güneydogu Anadolu region (Turkey), whilst

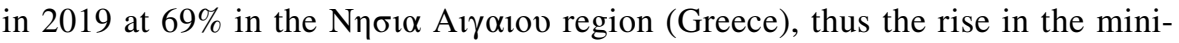
mum variable value was almost fourfold. The variable values increased in all the regions. The highest pace of change in the years 2010-2019, above 1, occurred in regions situated in Turkey, Bulgaria and Romania. The pace of change above 0.5 was also reported in Hungary, Italy and Spain. The highest absolute growth was observed in the region of Güneydogu Anadolu (Turkey), where the variable value rose by 63 percentage points from 18 in 2010 to $81 \%$ in 2019 .

Figure 3 presents statistical data and analyses for the OI variable, which was also very strongly spatially diversified. The highest percentage of individuals buying goods and services on the Internet, in all the analysed periods, occurred in regions of Norway, Sweden, Finland, Iceland, the United Kingdom, the Netherlands, Denmark, Germany, Switzerland and partly in France. An undisputed 


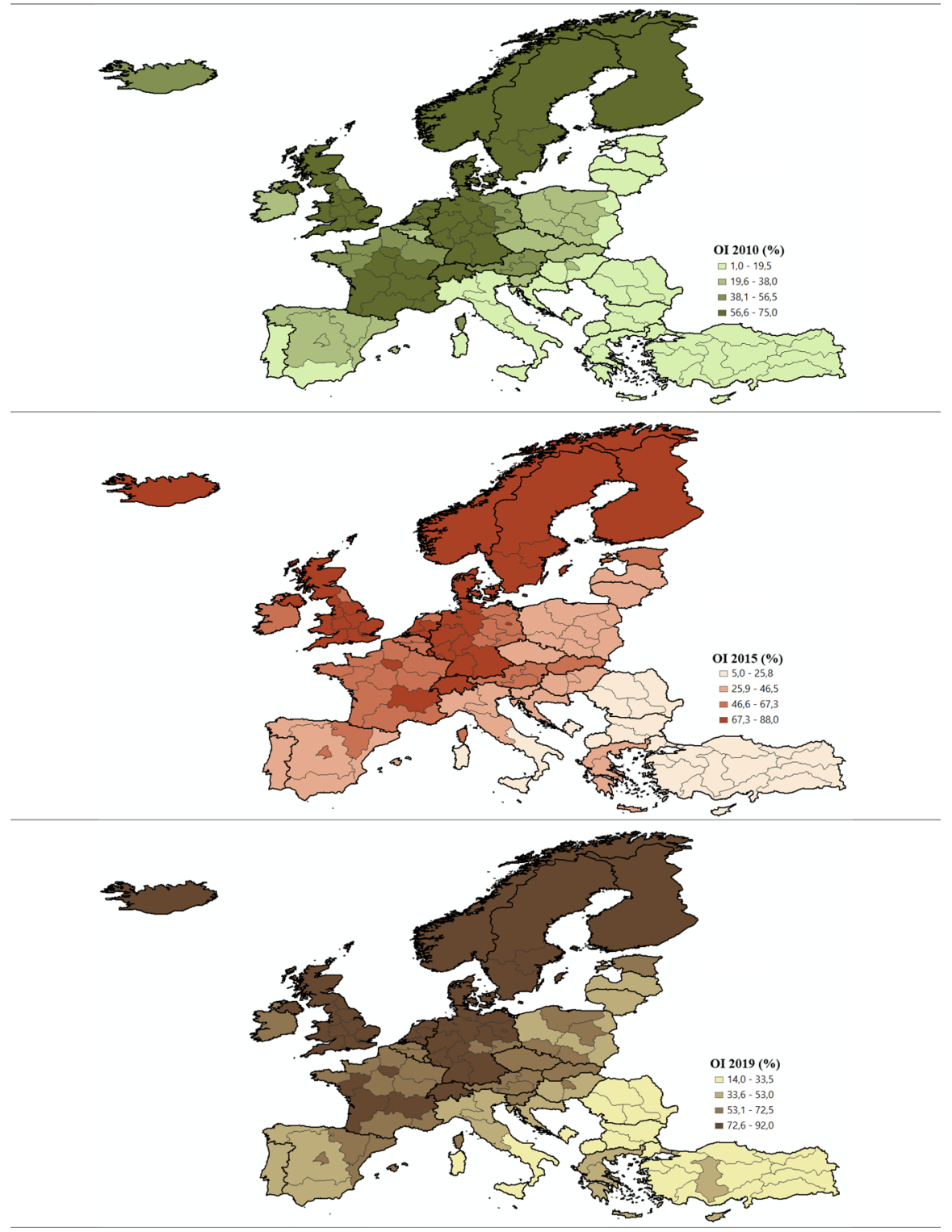

Fig. 3 Individuals who ordered goods or services over the internet for private use, last online purchase: in the 12 months (\% of individuals) in 2010, 2015, 2019, pace of change 2010-2019 and absolute growth 2010-2019 (percentage points). Source: own elaboration in ArcMap

leader was, however, all British regions, primarily South East (England), South West (England) and East of England, where the highest variable values were noted from 75 in 2010 to $92 \%$ in 2019 . The lowest value of the variable in all the 


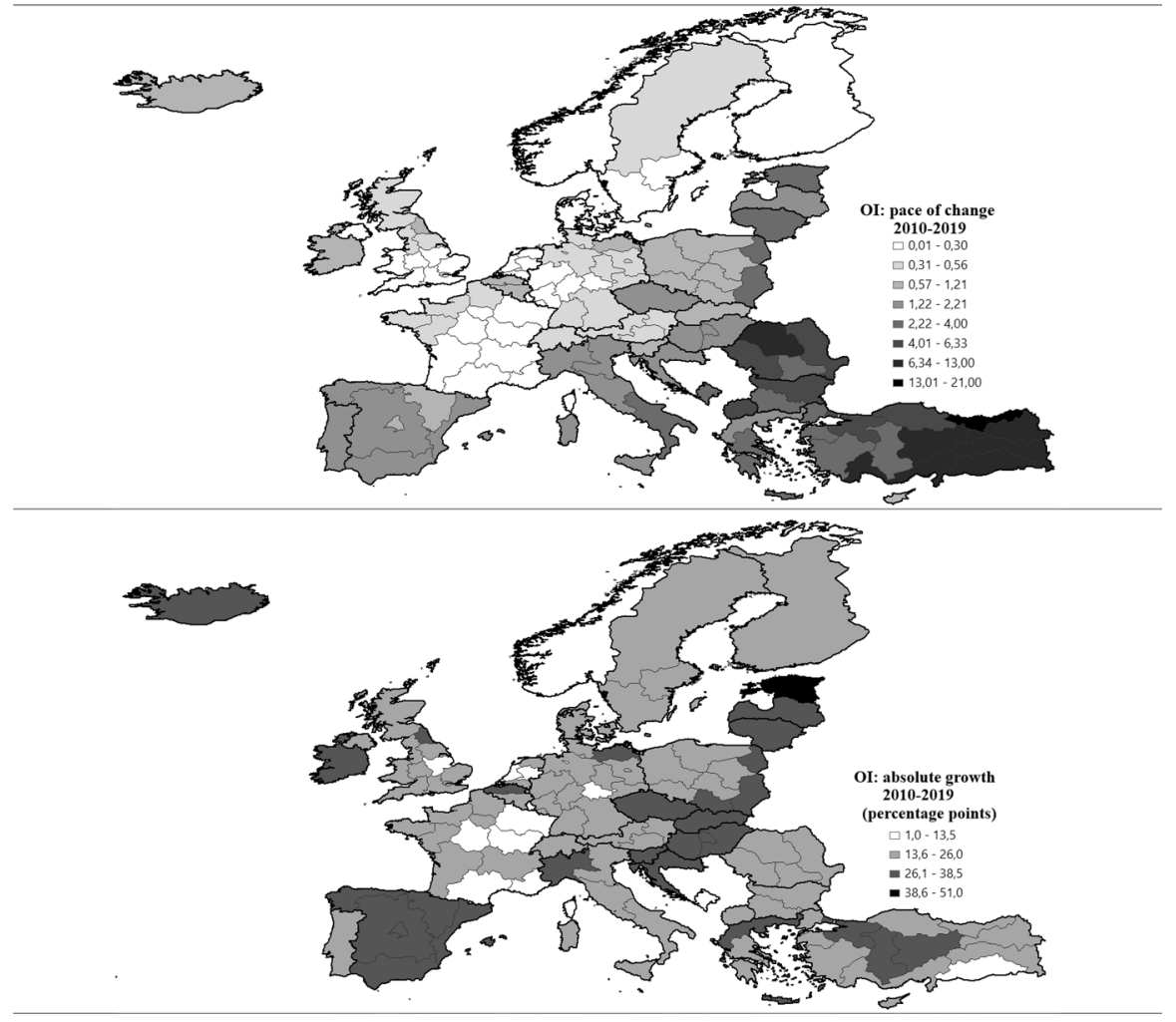

Fig. 3 (continued)

analysed years occurred in South-Eastern Europe, in regions located in Turkey, Bulgaria, Romania, Croatia as well as Southern Greece and Italy. The minimum variable value in both 2010 and 2019 was observed in the region of Güneydogu Anadolu (Turkey), at 1 and 14\%, respectively. The variable values increased in all the regions. The pace of change above 1 in the years 2010-2019 was reported in 48 regions (about $41 \%$ of the analysed spatial units) located mainly in Southern and Eastern Europe. In turn, the highest absolute growths were noted in Estonia (51 percentage points), the Czech Republic (37 percentage points), Latvia (37 percentage points), the Spanish region of Comunidad de Madrid (37 percentage points) and the Polish region Makroregion Wschodni (37 percentage points).

Spatial analyses of e-retail in Europe applied the spatial weights matrix in the form of the first-rank queen configuration. The first step was to determine values of the global Moran's I statistics for variables: FI, AI and OI in the years 2010-2019. Based on the results obtained (Table 2), it can be concluded that all variables showed strong positive spatial autocorrelation. In the case of the FI variable, the highest value of the global Moran's I statistic was observed in 2014: 0.841, and the lowest in 2019: 0.727—a slight fall in the statistic's value was noted in the study period. The AI variable showed the strongest spatial autocorrelation also in 2014: 
Table 2 Values of global Moran's I statistics for FI, AI and OI in 2010-2019. Source: own elaboration in GeoDa

\begin{tabular}{llll}
\hline Year & $\begin{array}{l}\text { FI } \\
\text { frequency of Internet } \\
\text { access: once a week } \\
\text { Moran's } I\end{array}$ & $\begin{array}{l}\text { AI } \\
\text { households with access to } \\
\text { the internet at home }\end{array}$ & $\begin{array}{l}\text { OI } \\
\text { individuals who ordered goods or ser- } \\
\text { vices over the internet for private use }\end{array}$ \\
\hline 2010 & 0.822 & 0.811 & 0.846 \\
2011 & 0.821 & 0.804 & 0.854 \\
2012 & 0.830 & 0.796 & 0.856 \\
2013 & 0.827 & 0.805 & 0.837 \\
2014 & 0.841 & 0.815 & 0.851 \\
2015 & 0.801 & 0.710 & 0.830 \\
2016 & 0.802 & 0.718 & 0.860 \\
2017 & 0.782 & 0.670 & 0.843 \\
2018 & 0.748 & 0.639 & 0.832 \\
2019 & 0.727 & 0.580 & 0.839 \\
\hline
\end{tabular}

Significance level $\alpha=0.05$, all values are statistically significant

0.815 with a consistent fall in the statistic's value-to 0.580 in 2019 . In turn, the OI variable was characterised by a relatively constant global Moran's I statistic's value in the whole study period. The minimum value was reported in 2015: 0.830 and the maximum one in 2016: 0.860. In 2019, the lowest value of the statistic was observed for the AI variable: 0.580 , and the highest for the OI variable: 0.839 .

The strong positive spatial autocorrelation confirms the occurrence of spatial relationships affecting the FI, AI and OI variables in European regions. These relationships may be of a different nature: economic, social or cultural. Their consequence is the occurrence of the clusters of regions characterised by similarly high and low values of the analysed variables in a geographical space (in Europe) [20]. The local Moran's I statistic answers the question about the location of the clusters in the study period. Figure 4 shows the results of the LISA analysis for all the variables in the first and last years covered by the study, i.e. 2010 and 2019, in order to identify possible differences.

On the map presenting the local Moran's I statistics for the FI variable in 2010, two clusters marked red, in which adjacent regions are characterised by high variable values (High-High), can easily be seen. The first of them was formed by countries located on the Scandinavian Peninsula, whereas the other-by regions belonging to the United Kingdom, Belgium, France, the Netherlands and Germany. These clusters were formed by 24 regions. In turn, 19 regions situated in Turkey, Greece, Bulgaria and Romania made up a cluster marked blue, in which adjacent units were characterised by low variable values (Low-Low). In 2019, the blue cluster looked the same. While the High-High clusters were expanded by further regions from the United Kingdom and Germany-the clusters were formed by 28 regions.

On the map presenting the local Moran's I statistics for the AI variable in 2010, the Low-Low cluster looked almost the same as for the FI variable, comprising 20 regions belonging to Turkey, Greece, Bulgaria, Romania and Hungary. The situation 


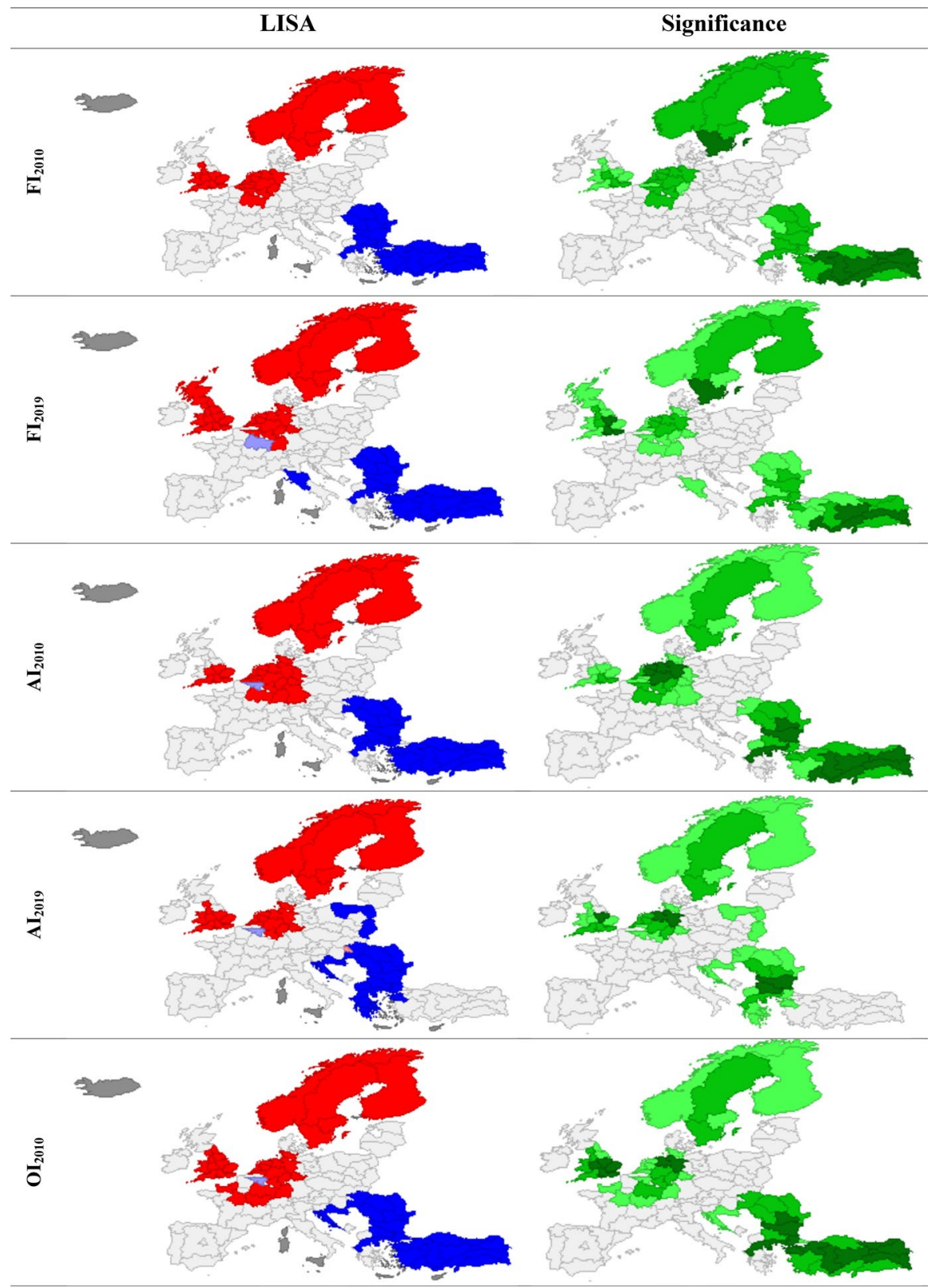

Fig. 4 Local Moran's statistic for FI, AI and OI in European regions in 2010 and 2019. Source: own elaboration in GeoDa

was also similar for the High-High clusters because they included 27 NUTS 1 units located on the Scandinavian Peninsula, in Germany, Belgium, the Netherlands and France. Considerable changes, however, took place in 2019, especially for the 


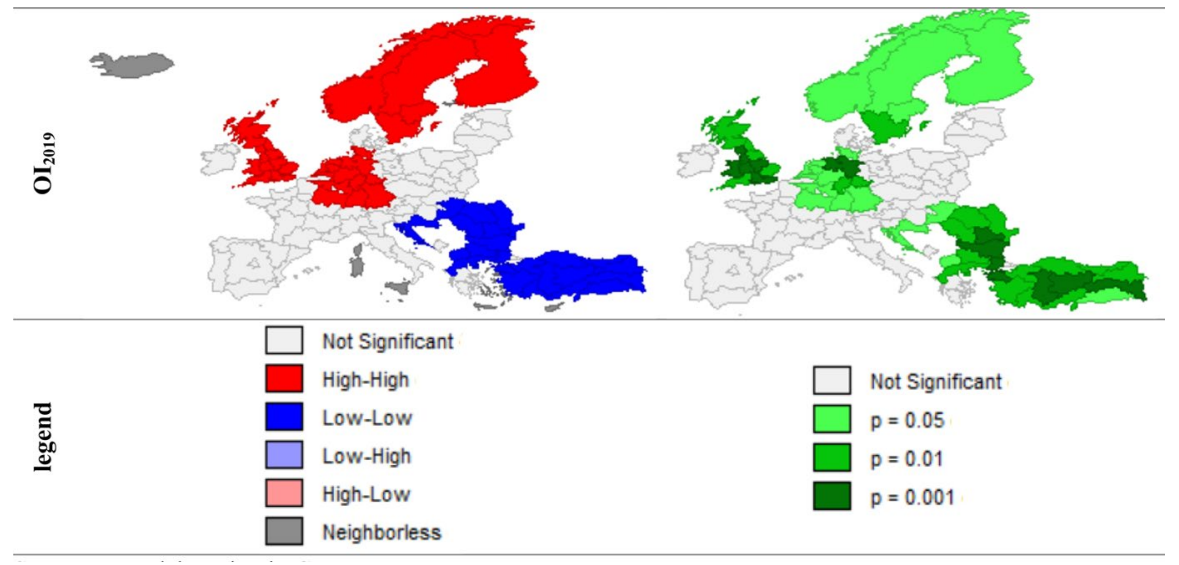

Fig. 4 (continued)

cluster identifying regions characterised by low variable values. The cluster comprised 15 regions: as compared to 2010, most Turkish units were eliminated, while Croatia and three Polish regions were included. On the other hand, changes were not as big for the High-High cluster. French and two German regions were excluded, while the cluster was joined by regions situated in the United Kingdom. The clusters were formed by 23 regions.

On the maps presenting the local Moran's I statistics for the OI variable, it can clearly be seen that the Low-Low cluster was the same in 2010 and 2019. It comprised 21 regions located in the East of Europe, in Turkey, Greece, Bulgaria, Romania, Hungary and Croatia. In 2010, the High-High clusters were formed by 30 regions situated mainly in the United Kingdom, Germany, France, the Netherlands and on the Scandinavian Peninsula. In 2019, the clusters comprised almost all regions of the United Kingdom; one German and three French regions were removed the clusters were also formed by 30 spatial units.

Summing up all the analyzes carried out in the study and simplifying the results to the country level, units that are characterized by high, average and low e-retail potential were specified. Table 3 shows that the largest number of countries has been qualified as average in this respect (13). However, there is only one less country at the high level (12), those units are located in the northern and western part of Europe. The low level in terms of e-retail has been assigned to 9 countries that are located in Eastern Europe. It can therefore be concluded that, in general, Europe is quite diversified in terms of e-retail. 
Table 3 The level of e-retail potential for European countries

\begin{tabular}{llll}
\hline Number & E-retail potential & & \\
\cline { 2 - 4 } & High & Average & Low \\
\hline 1 & Belgium & Austria & Bulgaria \\
2 & Denmark & Czech Republic & Croatia \\
3 & Finland & Cyprus & Greece \\
4 & France & Estonia & Hungary \\
5 & Germany & Ireland & Macedonia \\
6 & Iceland & Italy & Malta \\
7 & Luxembourg & Latvia & Montenegro \\
8 & the Netherlands & Lithuania & Romania \\
9 & Norway & Poland & Turkey \\
10 & Sweden & Portugal & \\
11 & Switzerland & Slovakia & \\
12 & United Kingdom & Slovenia & \\
13 & & Spain & \\
\hline
\end{tabular}

\section{Discussion}

The research confirms considerable spatial diversity of the analysed variables: frequency of Internet use, access to the Internet and online shopping. They were partly consistent with the division of e-retail in Europe into two clusters adopted in the literature within the framework of the north-south polarisation pattern, although the results obtained indicated rather a north-south-east e-commerce polarisation.

The thorough analysis of changes in access to the Internet in the years 2010-2019 leads to the conclusion that, despite the observed increasing accessibility in the Eastern regions of Europe, it did not translate into changes in online shopping that remained at a permanently low level. Access to the Internet constitutes one of the key factors in e-retail diffusion, which was particularly visible in large conurbations in Europe and Scandinavian countries. At the same time, in some countries, high broadband costs and unstable connections limit trust in this form of interaction with platforms and stores where online shopping can be done.

There were no significant changes in the cluster of regions characterised by a high level of online shopping either. This leads to the conclusion that a spatially and temporally stable digital divide exists in Europe, which shows that the Digital Single Market strategy does not bring about increased convergence. It may be caused by differences in household incomes, which means that wealthy regions accumulate most e-retail. Another probable cause can be the technological boundary connected with Internet acceptance as a safe, price-competitive and convenient shopping space. Nevertheless, e-commerce may be treated as a phenomenon characteristic of shopping preferences and patterns of households in cities, such as Paris, Madrid and Berlin, with limited diffusion to suburban areas.

In the case of frequency of Internet use, the research also confirmed a noticeable polarisation and concentration in regions belonging to Germany, the United 
Kingdom and Scandinavian countries. This may be connected with both Internet acceptance in everyday household behaviour patterns in those countries and highquality data transfer along with its common use, including online shopping.

The cultural context of e-retail in Europe indicates evident boundaries between Ireland and Northern Ireland, Northern and Southern parts of Belgium, Eastern and Western Germany, and among islands such as Corsica and Sardinia. The division was also seen in regions of Turkey. This spatial and temporal e-shopping diversity can be explained by considering cultural factors based on characteristic features of national cultures.

Spatial and temporal e-shopping diversity in Europe is also influenced by the e-commerce distribution chain architecture, which is both regionally and temporally diversified, as indicated by Amazon's investments. This results in differences in lastmile e-commerce logistics costs. The results obtained did not confirm the hypothesis that e-retailing is a phenomenon preferred by households living in rural and suburban areas. The clusters of regions in Germany and the UK indicate a higher level of space urbanisation as a typical area for online shopping diffusion. Nonetheless, the more rural regions in the Scandinavian countries do not conform to this perception indicating diversity on this aspect too.

\section{Conclusion}

This study contributes to developing e-SCM through determining the extent of e-commerce diversity in the retailing sector in Europe at the regional level in the years 2010-2019. The analyses were performed applying GIS and ESDA methods allowing the aim of the study to be achieved, and answering all the research questions posed. The results confirmed that e-retail was characterised by quite considerable regional diversity in Europe. The largest percentage of population using the Internet at least once a week (FI) and population with access to the Internet at home (AI) in all the analysed periods was found in regions situated in Northern and Western Europe (in Iceland, Norway, Sweden, Finland, the United Kingdom, Denmark, Germany and Switzerland), whereas the lowest was in regions located in the Eastern part of the continent (in Turkey, Greece, Bulgaria and Romania). The leader among regions characterised by the highest percentage of individuals buying goods and services online (OI) was British regions, while the lowest values were observed in Turkish ones. It was also observed that there was an increase in the values of the analysed variables in all the studied regions in the years 2010-2019 (in the case of the AI variable a fourfold increase in the minimum value was noted; the pace of change for the OI variable exceeding 1 was found in as many as 48 regions, which accounted for $41 \%$ of the studied spatial units). That means that both access to the Internet and frequency of its use, including for commercial purposes, significantly improved in Europe in the study period.

Based on the results of the spatial autocorrelation analysis, it is concluded that all the variables showed strong positive autocorrelation. In the clusters formed by regions located in the North-Western part of Europe (in Germany, the United 
Kingdom, the Netherlands, Belgium and on the Scandinavian Peninsula), there was the highest percentage of population using the Internet and buying goods and services online (excluding Belgium) in both 2010 and 2019. No considerable changes in that respect were observed over time. In turn, in the South-Eastern part of Europe (Turkey, Greece, Croatia, Romania, Hungary and Bulgaria), the cluster of adjacent regions with the lowest activity in that respect was identified in both 2010 and 2019.

The research represents a starting point for further analyses of e-commerce in retailing at the regional level in Europe. The next step will be to analyse the impact of the socioeconomic situation of particular regions on e-retail development and especially on the propensity to shop online. Most researchers believe that e-commerce depends on incomes which significantly influence technological savvy [30]. Thus, it can be assumed that households with higher incomes have higher propensity to possess computers and have access to the Internet. Nevertheless, along with incomes, other factors impacting on e-retail should also be taken into account, such as socioeconomic and demographic variables, cultural determinants or development of e-commerce logistics and e-SCM solutions, influencing the quality of and trust in e-commerce.

Funding Open access funding provided by UiT The Arctic University of Norway (incl University Hospital of North Norway).

Open Access This article is licensed under a Creative Commons Attribution 4.0 International License, which permits use, sharing, adaptation, distribution and reproduction in any medium or format, as long as you give appropriate credit to the original author(s) and the source, provide a link to the Creative Commons licence, and indicate if changes were made. The images or other third party material in this article are included in the article's Creative Commons licence, unless indicated otherwise in a credit line to the material. If material is not included in the article's Creative Commons licence and your intended use is not permitted by statutory regulation or exceeds the permitted use, you will need to obtain permission directly from the copyright holder. To view a copy of this licence, visit http://creativecommons.org/licen ses/by/4.0/.

\section{References}

1. Aljifri, H. A., Pons, A., \& Collins, D. (2003). Global e-commerce: A framework for understanding and overcoming the trust barrier. Information Management and Computer Security, 11(2-3), $130-138$.

2. Anselin, L. (1995). Local indicators of spatial association-LISA. Geographical analysis, 27(2), 93-115.

3. Anselin, L. Spatial Econometrics, B. Baltagi (ed.). (2001) Companion to econometrics.

4. Aoyama, Y., \& Schwarz, G. (2004). From mail order to e-commerce: Competition, regulation, and politics of nonstore retailing in germany. Urban Geography, 25(6), 503-527.

5. Berry, H., Guillén, M. F., \& Hendi, A. S. (2014). Is there convergence across countries? A spatial approach. Journal of International Business Studies, 45(4), 387-404.

6. Billon, M., Ezcurra, R., \& Lera-López, F. (2009). Spatial effects in website adoption by firms in European regions. Growth and change, 40(1), 54-84.

7. Billón, M., Ezcurra, R., \& Lera-López, F. (2008). The spatial distribution of the internet in the European Union: Does geographical proximity matter? European Planning Studies, 16(1), 119-142. 
8. Billon, M., Lera-Lopez, F., \& Marco, R. (2016). ICT use by households and firms in the EU: Links and determinants from a multivariate perspective. Review of World Economics, 152(4), 629-654.

9. Bruno, G., Esposito, E., Genovese, A., \& Gwebu, K. L. (2011). A critical analysis of current indexes for digital divide measurement. Information Society, 27(1), 16-28.

10. Cárdenas, I., Beckers, J., \& Vanelslander, T. (2017). E-commerce last-mile in Belgium: Developing an external cost delivery index. Research in Transportation Business and Management, 24, 123-129.

11. Childers, T.L.; Carr, C.L.; Peck, J.; and Carson, S. (2001). Hedonice and Utilitarian motivations online retail.pdf. Journal of Retailing, 511-535.

12. Çikrıkci, Ö. (2016). The effect of internet use on well-being: Meta-analysis. Computers in Human Behavior, 65, 560-566.

13. Clarke, G., Thompson, C., \& Birkin, M. (2015). The emerging geography of e-commerce in British retailing. Regional Studies, Regional Science, 2(1), 371-391.

14. Couclelis, H. (2004). Pizza over the internet: E-commerce, the fragmentation of activity and the tyranny of the region. Entrepreneurship and Regional Development, 16(1), 41-54.

15. Daniels, J. D., Radebaugh, L. H., Sullivan, D. P., \& Salwan, P. (2016). International business: Environments and operations (p. 133). Pearson.

16. Davis, F. D. (1989). Perceived usefulness, perceived ease of use, and user acceptance of information technology. MIS quarterly, 13, 319-340.

17. El-Agraa, A. M. (2011). The European Union: economics and policies (p. 1). Cambridge University Press.

18. Gibbs, J., Kraemer, K. L., \& Dedrick, J. (2003). Environment and policy factors shaping global e-commerce diffusion: A cross-country comparison. Information Society, 19(1), 5-18.

19. Giménez, C., \& Lourenço, H. R. (2008). e-SCM: Internet's impact on supply chain processes. The International Journal of Logistics Management, 19(3), 309-343.

20. Griffith, D. A. (2003). Spatial autocorrelation and spatial filtering: gaining understanding through theory and scientific visualization. Springer.

21. Hernández, B., Jiménez, J., \& Martín, M. J. (2010). Customer behavior in electronic commerce: The moderating effect of e-purchasing experience. Journal of Business Research, 63(9-10), 964-971.

22. Jorgenson, D. W., \& Vu, K. M. (2016). The ICT revolution, world economic growth, and policy issues. Telecommunications Policy, 40(5), 383-397.

23. Juaneda-Ayensa, E., Mosquera, A., \& Murillo, Y. S. (2016). Omnichannel customer behavior: Key drivers of technology acceptance and use and their effects on purchase intention. Frontiers in Psychology, 7, 1-11.

24. Kauffman, R., \& Kumar, A. (2008). Impact of information and communication technologies on country development: Accounting for area interrelationships. International Journal of Electronic Commerce, 13(1), 11-58.

25. Kim, T. Y., Dekker, R., \& Heij, C. (2017). Cross-border electronic commerce: Distance effects and express delivery in European union markets. International Journal of Electronic Commerce, 21(2), 184-218.

26. Kshetri, N., Bebenroth, R., Williamson, N. C., \& Sharma, R. S. (2014). Cross-national heterogeneity in e-retail spending: A longitudinal analysis of economic, technological and political forces. Electronic Commerce Research, 14(4), 585-609.

27. Latif, Z., Latif, S., Ximei, L., Pathan, Z. H., Salam, S., \& Jianqiu, Z. (2018). The dynamics of ICT, foreign direct investment, globalization and economic growth: Panel estimation robust to heterogeneity and cross-sectional dependence. Telematics and Informatics, 35(2), 318-328.

28. Lucendo-Monedero, A. L., Ruiz-Rodríguez, F., \& González-Relaño, R. (2019). Measuring the digital divide at regional level: A spatial analysis of the inequalities in digital development of households and individuals in Europe. Telematics and Informatics, 41, 197-217.

29. Lutz, S. U. (2019). The European digital single market strategy: Local indicators of spatial association 2011-2016. Telecommunications Policy, 43(5), 393-410.

30. Mahmood, M. A., Bagchi, K., \& Ford, T. C. (2004). On-line shopping behavior: Cross-country empirical research. International Journal of Electronic Commerce, 9(1), 9-30.

31. Marc, W. (2001). Confidence and confidentiality: Stimulating e-commerce in Europe. Foresight, $3(2), 135-139$.

32. Micu, A. E., Bouzaabia, O., Bouzaabia, R., Micu, A., \& Capatina, A. (2019). Online customer experience in e-retailing: Implications for web entrepreneurship. International Entrepreneurship and Management Journal, 15(2), 651-675. 
33. Moran, P. A. P. (1948). The interpretation of statistical maps. Journal of the Royal Statistical Society Series B (Methodological), 10(2), 243-251.

34. Motte-baumvol, B., Belton-chevallier, L., \& Dablanc, L. (2017). Spatial Dimensions of E-Shopping in France. Asian Transport Studies, 4(3), 585-600.

35. O'Rourke, K. H. (2019). Economic history and contemporary challenges to globalization. Journal of Economic History, 79(2), 356-382.

36. Onstein, A. T. C., Tavasszy, L. A., \& van Damme, D. A. (2019). Factors determining distribution structure decisions in logistics: A literature review and research agenda. Transport Reviews, 39(2), 243-260.

37. Ord, J. K., \& Cliff, A. (1973). Spatial autocorrelation. London: Pion.

38. Pérez-Amaral, T., Valarezo, A., López, R., Garín-Muñoz, T., \& Herguera, I. (2019). E-commerce by individuals in Spain using panel data 2008-2016. Telecommunications Policy. https://doi. org/10.2139/ssrn.3376544

39. Perrons, D. (2004). Understanding social and spatial divisions in the new economy: New media clusters and the digital divide. Economic Geography, 80(1), 45-61.

40. Shi, R., Chen, H., \& Sethi, S. P. (2017). A generalized count model on customers' purchases in $\mathrm{O}_{2} \mathrm{O}$ market. International Journal of Production Economics, 215, 121-30.

41. Smith, R., Deitz, G., Royne, M. B., Hansen, J. D., Grünhagen, M., \& Witte, C. (2013). Cross-cultural examination of online shopping behavior: A comparison of Norway, Germany, and the United States. Journal of Business Research, 66(3), 328-335.

42. Sujarwoto, S., \& Tampubolon, G. (2016). Spatial inequality and the Internet divide in Indonesia 2010-2012. Telecommunications Policy, 40(7), 602-616.

43. Thomas, P. (2018). The great convergence: Information technology and the new globalization. Business Economics, 53(1), 50-52.

44. Tolstoy, D., Jonsson, A., \& Sharma, D. D. (2016). The Influence of a retail firms geographic scope of operations on its international online sales. International Journal of Electronic Commerce, 20(3), $293-318$.

45. Wigand, R. T. (1997). Electronic commerce: Definition, theory, and context. Information Society, 13(1), 1-16.

46. Wu, P. J., \& Lin, K. C. (2018). Unstructured big data analytics for retrieving e-commerce logistics knowledge. Telematics and Informatics, 35(1), 237-244.

47. Yadav, M. S., \& Varadarajan, P. R. (2005). Understanding product migration to the electronic marketplace: A conceptual framework. Journal of Retailing, 81(2), 125-140.

48. Yu, Y., Wang, X., Zhong, R. Y., \& Huang, G. Q. (2017). E-commerce logistics in supply chain management Implementations and future perspective in furniture industry. Industrial Management and Data Systems, 117(10), 2263-2286.

49. Zhang, Y., Chen, J., \& Zhang, S. (2017). Analysis of spatial pattern and influencing factors of e-commerce. International Archives of the Photogrammetry Remote Sensing and Spatial Information Sciences-ISPRS Archives, 42, 1461-1467.

50. Zwass, V. (2003). Electronic commerce and organizational innovation: Aspects and opportunities. International Journal of Electronic Commerce, 7(3), 7-37.

Publisher's Note Springer Nature remains neutral with regard to jurisdictional claims in published maps and institutional affiliations. 